\title{
The Development of Interactive Computer-Based Media for Learning Probability Subject in Mathematics Class
}

\author{
Yenita Roza, Kartini, Arisman Adnan, Habiburrahman \\ Mathematics Education Department \\ Universitas Riau \\ Pekanbaru, Indonesia \\ yenita.roza@lecturer.unri.ac
}

\begin{abstract}
The probability subject is found as an interesting topic for the students but the limitation of the learning media becomes an obstacle in understanding this subject. This research aimed to develop computer-based media for learning probability subject in mathematics class at grade XI of senior high schools. This interactive learning media was developed by using an ADDIE development model. The topics were probability, combination and permutation. The development was conducted through the following steps: (1) analysis; (2) design; (3) development; (4) implementation and evaluation. At the stage of analysis, the researcher conducted a needs analysis for Core Competence (CC) - Basic Competence (BC) analysis, analysis of students' problems, and material analysis. The researchers collected materials from related books used by students and teacher in the class to design the learning media. The learning media that had been developed was validated by five validators and revised based on the input from the validators. The validation of the media involved aspects of curriculum, learning, display, and program. The valid learning media was tested in two stages. The first one used the small group test with subjects of five students and the second used large group test with subjects of 30 students. Based on the data analysis, it can be concluded that the computer-based media for learning mathematics on probability subject is valid with average score for each aspects of more than 3.71, and gains a good responses from students.
\end{abstract}

Keywords-Computer-Based Learning Media, Probability, Research and Development

\section{INTRODUCTION}

The development of technology has always been progressing very quickly, especially in the field of computers. Computers are used in various sectors, including the public sector, the economy, and education. The computers used in teaching can accelerate the learning process. Learning materials delivered through the computer are easily understand by students. Learning using computer media can encourage students to do exercises and to perform simulations because the availability of animations, color and music [1]. Computer media has the potential to cause a direct interaction between students and the topic, provide immediate feedback and increase interest in learning [2]
The use of technology in learning is also one of the demands of the 2013 curriculum. This curriculum focuses on student learning, which means learning is no longer focused at the activity of teachers so that the teachers do not always explain learning materials to the class. Students should actively build knowledge, as mentioned in the 2013 curriculum. Moreover, the teacher should facilitate the students to build their knowledge independently. A form of effort to have student center learning is by using learning media, such as computer-based learning media.

The problems in statistical learning in secondary education are the stages of motivation, digging experience, the formation of knowledge and automation of knowledge [3]. This phase can be facilitated by the use of computers in learning. In mathematics, the subject of probability uses various learning activities, such as determining the chance of throwing the dice toss. The learning activity is done frequently and if done by each student, it will take a long time. Nevertheless, it is very important that the learning activity is carried out by the students as it will help in understanding the probability. Throwing dice or coins in large quantities can be effectively done using a computer. Based on the results of the survey interviews with some high school mathematics teachers, the researchers found that in teaching probability especially in conducting activities of throwing dice or coins, the teachers do not give direct experience for students to perform those activities. When students build knowledge with direct activity they will get the good effect to learn and more motivated. Solving the real problem is also the key to success in statistical learning [4].

Based on the aforementioned problems, there must be a way that the activities in the learning probabilities, especially in the events of roll dice or coins, can be performed by each of the students effectively. According to the researchers, computers become a solution in which computers are able to visualize the activities of learning probabilities accurately and attractively. Thus, the researchers wanted to develop a computer-based instructional media with interactive tutorial models for class XI on topics of probabilities. The study produced computer-based instructional media that is valid and 
conforms to the standards of practicalities to be used by students of class XI for learning probabilities.

\section{METHOD}

This study was a research and development (R \& D), which aimed to produce a computer-based media with interactive tutorial models for learning probability subject in mathematics class for grade XI of senior high school. This development research used ADDIE development model using the following steps: (1) analysis; (2) design; (3) development; (4) implementation; (5) evaluation [5].

The subjects of this study in the small group test were five students with the heterogeneous academic ability and gender from class XI of Senior High School Babussalam Pekanbaru. The subjects of large group test were students of class XI of Senior High School Babussalam Pekanbaru with total of 30 students with heterogeneous academic skills. The instruments for collecting data in this study were validation sheet and student response sheet. Validation sheet consisted of a media validation sheet (to assess aspects of the display and the program) and material validation sheets (aspects of the curriculum and learning assessment). Each validation sheet consisted of four alternative answers, namely 1, 2, 3, and 4, which were categorized as very low, low, good and excellent, respectively. Student responses to the questionnaire included statements that were divided into three aspects: media, the subject, and display. Student responses to the questionnaire consisted of five alternative answers, i.e. strongly agree, agree, a bit agree, disagree, and strongly disagree.

In the validation phase, the learning media is assessed by validator using validation sheet. The validation Sheets from each validator were analyzed, and comment and suggestions from validators were used as the basis for improving the media prior to the trial. In the small group trial, the media was run by each of the students in the computer lab under the researchers' guidance. The qquestionnaire was completed by the students. The analysis of the cycle process was used as the basis for the evaluation and improvement of the media for the large group trial. After conducting the large group trial, the media was revised based on the replies to the questionnaire in large group trial. Data analysis techniques in this study consisted of validation sheet analysis and analysis of student responses in the questionnaire. The analysis of the validation sheet was done by using the following formula.

Mean of each indicator from 5 validators was calculated using the following formula:

$$
K_{i}=\frac{\sum_{h=1}^{N} V_{h i}}{N}
$$

Mean of each aspect of validation was calculated using the following formula:

$$
A_{i}=\frac{\sum_{i=1}^{n} K_{i j}}{n}
$$

Overall mean of validation was calculated using the following formula:

$$
R T V=\frac{\sum_{i=1}^{N} A_{i}}{N}
$$

After an average total validation is obtained, the total average was matched with the validity criteria $3 \leq \mathrm{RTV} \leq 4$ considered valid $2 \leq \mathrm{RTV}<3$ categorized quite valid, $1 \leq \mathrm{RTV}<2$ considered invalid.

The calculation of the percentage of students' response was done by giving a score for each item statement in the student questionnaire responses based on the chosen alternative options. The options were strongly agree, completely agree, agree, disagree and strongly disagree indicated by 5, 4, 3, 2 and 1 respectively. The next step was to calculate the percentage of responses for each aspect by the following formula:

$$
R_{i}=\frac{\sum_{j=1}^{m} P_{j}}{\text { Skor maksimal aspek ke }-\mathrm{i}} \times 100 \%
$$

After calculating the percentage of responses for each aspect, the average percentage of the total was calculated by using the formula:

$$
R T=\frac{\sum_{i=1}^{m} R_{i}}{m}
$$

Furthermore, after calculating the total percentage, categories of responses were determined by using the following categorizations: $85 \% \leq \mathrm{RT}$ excellent category, $70 \%$ $\leq$ RT $<85 \%$ good category, $50 \% \leq$ RT $<70 \%$ unfavorable category, RT $<50 \%$ is not good category.

\section{RESULTS AND DISCUSSION}

\section{A. Analysis}

Activities in this phase involved the problem definition, analysis of basic competencies and the analysis of probability topics.

1) Problem Defined: Based on observations and the researchers' interviews with teacher about the learning activity, the researchers found a number of claims in statements of problems and solutions.

- $\quad$ Problem 1 
Probability is one topic in mathematics with simple numerical calculation level, but it takes a strong analysis and the right mindset. For example, determining the composition of a some digits of given numbers was getting difficult if students get condition as this one: how many three-digit odd numbers of more than 300 can be made of the numbers $1,4,6,8,9$ ?

- Solution:

In the media, the definitions and concepts are provided using an easily understood language and the right thought process that was understood by overcoming students

- Problem 2

Probability topic needs many simple experiments like throwing dice and coins. The experiment using a small dice or coin, however, is difficult to demonstrate in front of the big class.

- Solution:

In the media, experiments of rolls the dice and coins are provided and easily performed repeatedly for students as their learning needs.

- Problem 3

On probability topic, students are required to write the sample space to understand and work on the problems. The sample space of the roll of two dice has 36 sampling points, and the students need to spend a long time in learning the topics.

- Solution:

A presentation in easily understood form gives steps in determining the sample space and streamline of the time.

- Problem 4

The probability topic has plenty contextual examples. Yet many students had problem in understand the relation in the topic. The inability of the students in understanding the probability in real-life examples will make this material difficult to understand.

- Solution:

An example is given in the form of images that can help students' understanding.

2) Analysis of Basic Competencies and Probability Topic: Analysis of basic competencies and topics probability was done to define basic competencies (KD) used in developing learning media. The basic competencies for the development of instructional media are as follows:

3.13) Describe and apply various rules of counting slot through some real examples and algorithm of counting slot (multiplication, permutations and combinations) through diagrams or other means.

3.15) Describe the concept of sample space and determine the probability of an event in an experiment.

3.17) Describing the concept of probability of an event and use it in problem solving.

Under the Basic Competences, the probability topic presented on the development of instructional media are as follows: understanding counting slots, filling slots, definition of factorial notation, permutations, combinations, probability of single event, probability of multiple event, independent event and conditional events. These materials were divided into six class meetings with the following description:

\section{Class Meeting 1}

1. Definition of Counting Slot

Counting Slot is a rule used to determine or calculate how many ways the case of an event. Counting slot consists of the filling of slots, permutations and combinations.

a. Filling slots

When a first event can be solved by k1 different ways, the second event can be performed in $\mathrm{k} 2$ various ways, and so on up to the events of $n$, then the number of different ways all of these events is $\mathrm{K}$, in which:

$\mathrm{K}=\mathrm{k} 1 . \mathrm{k} 2$. $\mathrm{k} 3 \ldots \mathrm{kn}$

To determine the number of available places, we use the product operation as well as other means such as a tree structure, cross-table, and sequences of numbers

Example:

Suppose there are two black and blue pants and four shirts of yellow, red, white and purple. How many pairs of pants and shirt colors can be formed?

Answer:

By the rules of multiplication, there are two possibilities pants and four possibilities for shirt which means that the number of different pair combination can be used is $2 \times 4=8$ pairs of different pants and shirt.

By using the crosstabs.

TABLE I. THE CROSSTABS

\begin{tabular}{|c|l|l|l|l|}
\hline & Yellow (k) & \multicolumn{1}{|c|}{ Red (m) } & White (p) & Purple (u) \\
\hline Black (h) & $(\mathrm{h}, \mathrm{k})$ & $(\mathrm{h}, \mathrm{m})$ & $(\mathrm{h}, \mathrm{p})$ & $(\mathrm{h}, \mathrm{u})$ \\
\hline Blue (b) & $(\mathrm{b}, \mathrm{k})$ & $(\mathrm{b}, \mathrm{m})$ & $(\mathrm{b}, \mathrm{p})$ & $(\mathrm{b}, \mathrm{u})$ \\
\hline
\end{tabular}

By using Tree Diagram.

Fig. 1. Tree Diagram

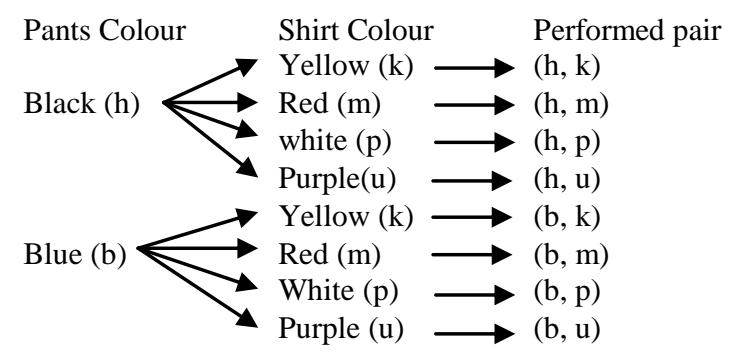

Using the ordered pair.

Suppose the set of pants color is expressed by $A=\{h, b\}$ and set the color of clothes is $B=\{k, m, p, u\}$. The set of ordered pairs of set A and set B can be written $\{(\mathrm{h}, \mathrm{k}),(\mathrm{h}, \mathrm{m})$, $(\mathrm{p}, \mathrm{p}),(\mathrm{h}, \mathrm{u}),(\mathrm{b}, \mathrm{k}),(\mathrm{b}, \mathrm{m}),(\mathrm{b}, \mathrm{p}),(\mathrm{b}, \mathrm{u})\}$. Many elements are in the set of ordered pairs with 8 kinds of color pairs. 


\section{Class Meeting 2}

1. Definition of Factorial Notation

$\mathrm{n}$ factorial is the product of the positive integers from 1 to $\mathrm{n}$. The notation of $\mathrm{n}$ factorial is denoted by $\mathrm{n}$ ! (Pronounced " $\mathrm{n}$ factorial"), for example $4 !=1 \times 2 \times 3 \times 4$

2. Permutation

a. Permutation of different elements

$\mathrm{K}$ arrangement of different objects from $\mathrm{n}$ objects is provided where $\mathrm{k} \leq \mathrm{n}$ is often popularized by the term $\mathrm{k}$ permutation of different objects from $n$ objects available. Many permutations of k objects from $\mathrm{n}$ objects in writing $\mathrm{P}(\mathrm{n}, \mathrm{k})$ or $P_{k}^{n}$ can be formulated:

$$
P_{k}^{n}=\frac{n !}{(n-k) !}
$$

b. Permutation which contains the same element.

The number of permutations $P(n, n)$ with similar object, $b$ the same object, and so on written P, were formulated as follows:

$$
P=\frac{n !}{a ! b ! \ldots}
$$

c. Cyclic permutations

If there are two objects sitting in a circle, then a lot of composition no $1=(2-1)$ !, namely:

Fig. 2. Two objects sit in a circle

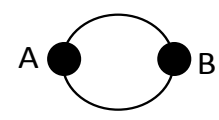

If there are three objects sitting in a circle, then a lot of composition no $2=(3-1)$ !, namely

Fig. 3. tree objects sit in a cilcle

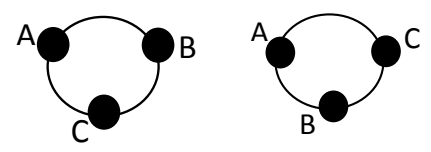

If there are $\mathrm{n}$ objects sitting in a circle, then a lot of the arrangement taking place there (n - 1)! Thus, the definition is obtained: If there are $\mathrm{n}$ distinct objects and arranged in the form of cyclic (circular), then the number of arrangements that occur (permutation $\mathrm{P}$ cyclic or cyclic) is: $P_{\text {siklis }}=(n-1)$ !

\section{Combination}

The composition of the object with the order $\mathrm{k}$ of $\mathrm{n}$ objects are not considered available where $\mathrm{k} \leq \mathrm{n}$ often popularized by the term combination of $\mathrm{k}$ objects from $\mathrm{n}$ objects available. The number of combinations of $\mathrm{k}$ objects from $\mathrm{n}$ objects in writing $\mathrm{C}(\mathrm{n}, \mathrm{k})$ or $C_{k}^{n}$ formulated:

$$
C_{k}^{n}=\frac{n !}{(n-k) ! k !}
$$

\section{Class Meeting 3}

1. Definition of Sample Space and Events

At trial of throwing a coin metal, the emerging results can be written using the set notation. Suppose the "G" is meant the emergence of the image and the "A" appearance of the figure. The set of all the above results that may arise at trial written $S$ $=\{G, A\}, S$ is called the sample chamber or sample chamber. Thus, the sample space is the set $\mathrm{S}$ of all event or events that may arise from an experiment. The sample space is usually denoted by the letter " $S$ " referring to as the set of rules. Members of the sample space are called sample points. For example, sample space $S=\{G, A\}$ has a 2 point example, the $\mathrm{G}$ and $\mathrm{A}$ are referred to as members of the set universe. The number of members of the sample chamber generally denoted by $n(S)$.

Each time the experiment will result in event or occurrence. For example, a coin throwing activities will appear side of the picture $(G)$ or the appearance of the figure (A). Activity throwing a six-sided dice will obtain the results of events that may appear one of the six sides of the dice $1,2,3,4,5$, or 6 .

Thus, the results of the incident is a subset of the sample space. An event $A$ is a set of sample points or a subset of the sample space $S$. The set is empty or \{\} and $S$ itself is a subset of $S$, so it is an event. $\varphi$ called the incident is unlikely (impossible), while the $S$ referred to events that are certain.

2. Definition of Event Probability

Before knowing the definition of probability of occurrence, students should know first relative frequency. The relative frequency is the ratio between the numbers of results that appear with the number of tests conducted. For instance trial throws a coin 12 times. If a "G" 7 times and the rest appear "A" then the relative frequency of the emerging picture of $\mathrm{Fr}$ $(\mathrm{G})=7 / 12$ and relative frequency appears Score $\operatorname{Fr}(\mathrm{A})=5 /$ 12dengan thus relative frequency appears $G$ or $A$ approaches $1 / 2$, written $P(A)=P(G)=1 / 2$. So a trial which has some of the results, each has an equal chance formulated:

$$
P(A)=\frac{n(A)}{n(S)}
$$

\section{Class Meeting 4}

1. Frequency of Expected Event

An event expected frequency $\mathrm{Fh}$ of a trial is the product of probability $\mathrm{P}(\mathrm{A})$ to the number of trials $\mathrm{n}: F h=P(A) \times n$

Example:

Three two-sided coin image $(\mathrm{G})$ and numbers (A) are thrown together as many as 80 times, specifying the advent expectations. What are all three figures?

Answer:

$\mathrm{S}=\{$ GGG, GGA, GAG, AGG, AAG, AGA, GAA, AAA $\}$, so $\mathrm{n}(\mathrm{S})=8$

$\mathrm{A}=\{(\mathrm{AAA})\} ; \mathrm{Fh}($ all are number $)=\mathrm{P}(\mathrm{A}) \times \mathrm{n}=\frac{1}{8} \times 80=10$ times

2. Complements Probability of Event

Suppose the number of sample space is $n(S)$, the number of an event $A$ is $n(A)$. The number of events that is not $A$ or 
complement of A denoted Ac is: $\mathrm{n}(\mathrm{Ac})=\mathrm{n}(\mathrm{S})-\mathrm{n}(\mathrm{A})$, if the left and right sections divided by $\mathrm{n}(\mathrm{S})$, it will obtain the equation:

$$
\frac{n\left(A^{c}\right)}{n(S)}=\frac{n(S)}{n(S)}-\frac{n(A)}{n(S)} \leftrightarrow P\left(A^{c}\right)=1-P(A)
$$

\section{Class Meeting 5}

1. Probability of Multiple Event

Multiple event is an event that is formed by combining two or more simple events. By utilizing the operation between the set, we will determine likelihood compound. Operation between the set is a combination of the two sets and slices of the two sets.

Suppose the six dices are tossed at once. Probability A appears as primes number, i.e. $\mathrm{A}=\{2,3,5\}$ and $\mathrm{B}$ events appear an even number, i.e. $B=\{2,4,6\}$. In a Venn diagram, the two events above can be described as follows:

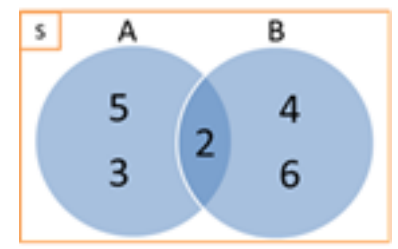

Fig. 4. Venn diagram

It show that event $\mathrm{A}$ and $\mathrm{B}$ are not independent (having subset $A \cap B=\{2\})$ From combination operation of two set, students obtain $\mathrm{n}(\mathrm{A}$ U B $)=\mathrm{n}(\mathrm{A})+\mathrm{n}(\mathrm{B})-\mathrm{n}(\mathrm{A} \cap \mathrm{B})$

$$
\begin{aligned}
& \frac{n(A \cup B)}{n(S)}=\frac{n(A)}{n(S)}+\frac{n(B)}{n(S)}-\frac{n(A \cap B)}{n(S)}, \text { conclude } \\
& P(A \cup B)=P(A)+P(B)-P(A \cap B)
\end{aligned}
$$

\section{Class Meeting 6}

1. Conditional and independent event

Let A and B are events in a sample space S. A and B refer to two events which are independent if the occurrence of events are not affected by the occurrence of other events. Thus it can be said that: Events $\mathrm{A}$ and $\mathrm{B}$ are independent if and only if $P(A \cap B)=P(A) \times P(B)$. If $P(A \cap B) \neq P(A) \times P(B)$, then the event $\mathrm{A}$ and $\mathrm{B}$ are dependent.

Example:

Two blue and white dices are thrown together. $\mathrm{A}$ is the number 4 on the blue dice appearance and $\mathrm{B}$ is the event number 3 on the white dice appearance. Are events A and B two independent events? If so, specify the number four chances appear on the dice blue and white number 3 on the dice.

Answer:

The appearance of the number 4 on blue dice does not affect the appearance of the number 3 on the white dice, so that the two events are independent. $\mathrm{A}=\{(4,1),(4,2), \ldots,(4,6)\}$ and

$$
\begin{aligned}
& \mathrm{B}=\{(1,3),(2,3), \ldots,(6,3)\} . \text { So } \mathrm{P}(\mathrm{A} \cap \mathrm{B})=\mathrm{P}(\mathrm{A}) \times \mathrm{P}(\mathrm{B})= \\
& \frac{1}{6} \times \frac{1}{6}=\frac{1}{36} .
\end{aligned}
$$

If one of the events influence the occurrence of other events, the two events are not mutually independent (conditional events). The incident occurred conditionally:

$$
P(A \cap B)=P(A) \times P(A \mid B)
$$

\section{B. Design Phase}

In the design phase, the activities included were: using flowchart design, designing the program in the form of branches, collecting material, and creating a preliminary design of the program display. Flowchart was made to assist the researchers' work on the development of the computer-based learning media.

1) Flowchart Design: Flowchart in the design phase is a chart that shows the flow of developed media. In other words, it is a graphical description of the sequences in running developed learning media for probability. Flowchart made for the development of instructional media starts from opening to closing a program. It aims to assist the researchers' work on the development of the computer-based media for mathematic learning with interactive tutorial models for class XI on probability topic.

2) Program Design: To facilitate researchers in designing a link of each page in the media created, the researchers designed the program in the form of branching.

3) Finishing the flowchart design: The researchers collected all materials needed to make the program. The collected material was in the form of images, animations, training materials taken from textbooks and Internet materials. The researchers installed additional applications to help the development of this learning media.

4) Designing the Program Display: After creating the program design, the researchers began to make preliminary design of the display, the autorun, frontpage pages and teaching material.

\section{Program Development}

During the development phase, the media was created by combining text, animation and image in harmony to produce a good and attractive display. Images and animations were processed with Adobe Photoshop CS 3 and Macromedia Flash 8. Web pages were created using Microsoft Office FrontPage 2003, pages for topics created with Microsoft Office PowerPoint 2007. Then, they were put all together via the link in an application using the autorun program of Pro Enterprise Longition AutoRun. At this stage, the activities were divided into three groups: the realization phase autorun, realization and realization front page display materials.

\section{Implementation and evaluation}

At this stage, the researchers validated the initial prototype of instructional media that has been made based on the initial design on phase of the design. The validation result was analyzed and then used as material improvement and 
refinement of an early prototype of instructional media. Furthermore, the researchers tested the prototype of instructional media for students to see the response to media prototypes. The test was done in two stages, the small group trial conducted with 5 students of class XI High School Mathematics Babussalam and large group trial conducted on 30 students of class XI High School Mathematics Babussalam Pekanbaru.

1) The Validation Score of the Instructional Media

TABLE II. The VAlidation Score of the Instructional Media

\begin{tabular}{|c|c|c|c|c|c|c|}
\hline \multirow{2}{*}{$\begin{array}{c}\text { Class } \\
\text { Meet- } \\
\text { ing }\end{array}$} & \multicolumn{3}{|c|}{ Mean of each aspect $\left(A_{i}\right)$} & \multirow[b]{2}{*}{$\begin{array}{l}\text { Pro- } \\
\text { gram }\end{array}$} & \multirow{2}{*}{$\begin{array}{l}\text { Mean } \\
(R T V)\end{array}$} & \multirow{2}{*}{$\begin{array}{c}\text { Valida } \\
\text {-tion } \\
\text { catego } \\
\text {-ry }\end{array}$} \\
\hline & $\begin{array}{c}\text { Curricu } \\
\text { llum }\end{array}$ & $\begin{array}{c}\text { Lear- } \\
\text { ning } \\
\text { Activity }\end{array}$ & $\begin{array}{c}\text { Cosme- } \\
\text { tics }\end{array}$ & & & \\
\hline 1 & 3.86 & 3.71 & 3.68 & 3.92 & 3.79 & Valid \\
\hline 2 & 3.88 & 3.85 & 3.75 & 3.92 & 3.85 & Valid \\
\hline 3 & 3.86 & 3.95 & 3.75 & 3.75 & 3.82 & Valid \\
\hline 4 & 3.81 & 3.95 & 3.62 & 3.71 & 3.77 & Valid \\
\hline 5 & 3.81 & 3.91 & 3.75 & 3.71 & 3.79 & Valid \\
\hline 6 & 3.86 & 3.80 & 3.75 & 3.64 & 3.76 & Valid \\
\hline
\end{tabular}

a) Suggestions / feedback by the validator: Once validated, instructional media was revised and improved based on suggestions and correction from validators. At the first class meeting of the validator suggestion, it was necessary to add material on the sum rule for the first class meeting. Then in the first class meeting, the researchers added a discussion of the rules of summation as in Fig. 5.

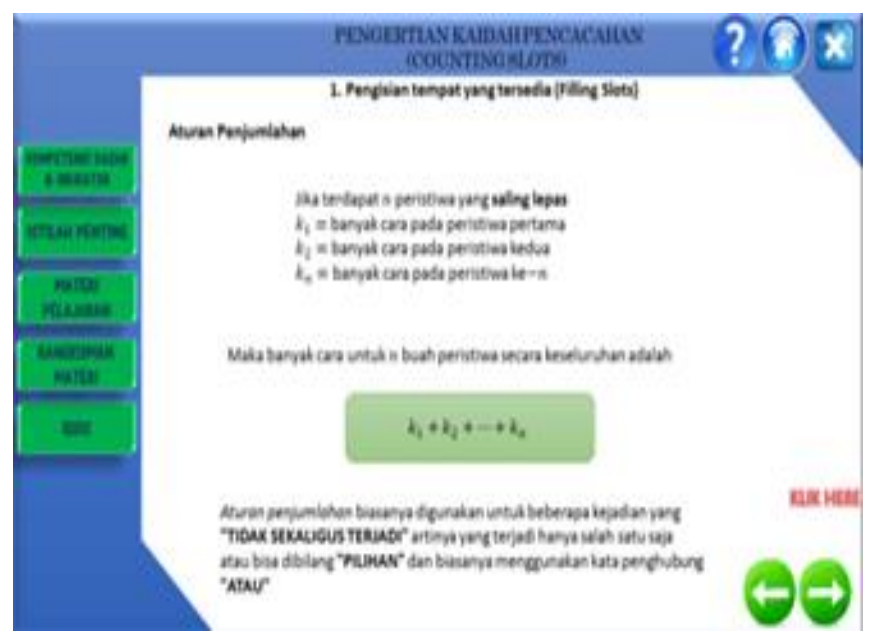

Fig. 5. Revision of Addition Rules

For class meeting 1, validators' feedback was on general improvement, such as there was a link to the power point in lesson material thas was not performed properly. By revision, overall all links ran well. In the aspect of the screen, the validator suggested to reduce and avoid using colors that were hard to see, such as the colors which were too bright or too soft. The change can be seen in Fig. 6 and Fig. 7 .

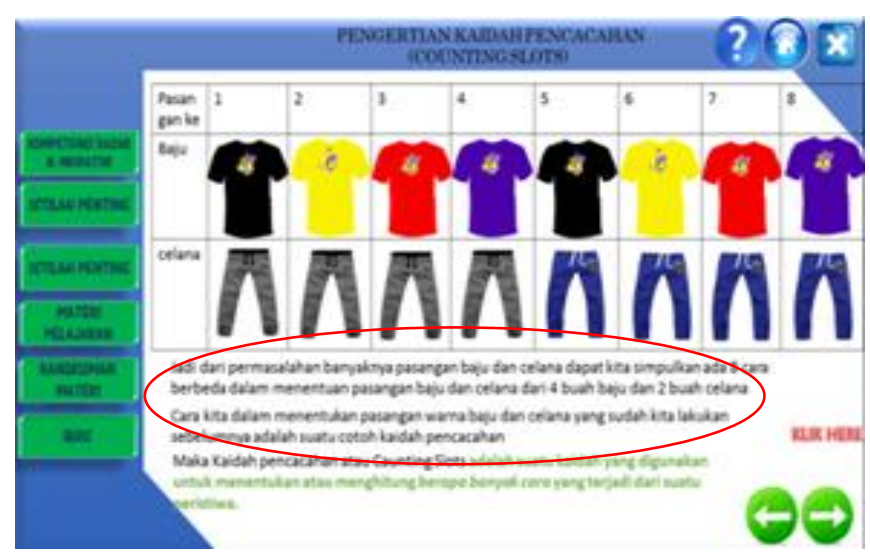

Fig. 6. The colour before revision

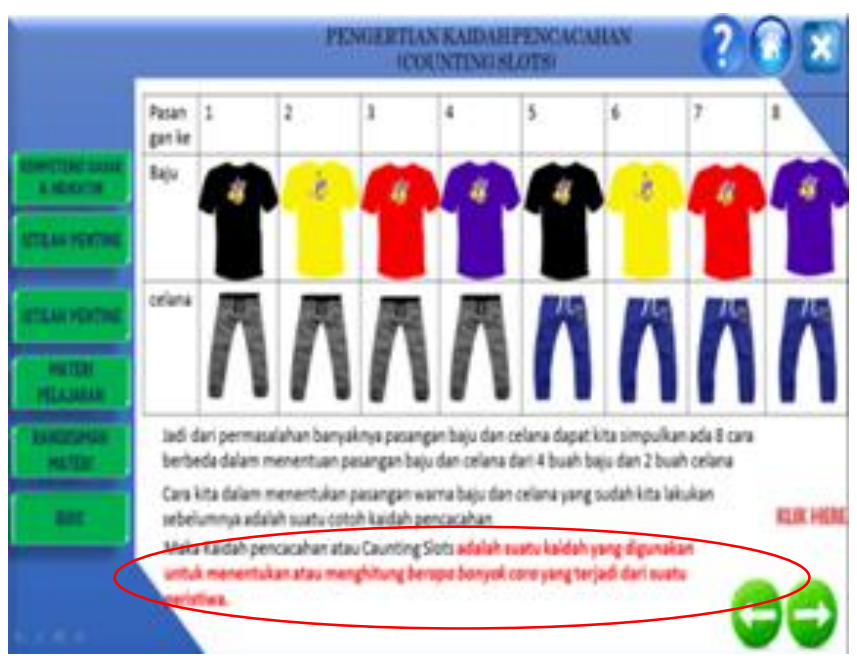

Fig. 7. The colour after revision

In class meeting 3 , the validator suggested the improvements of dice animation because it did not work when clicked. In this case, the researchers found the solution of the problem which was before running the media. The user must first install Macromedia Flash 8, then the application was included in a package with the media. As the menu system requirements, the researchers explained to the user for installing the Macromedia Flash 8 that available on learning media. For class meeting 5 , the validator suggested to put more examples of problems, so students could understand better. Then, the researchers have added two additional examples of problems. At class meeting of 6 , the validator suggested changes of the indicator at class meeting 6 to be adapted to the basic competence. Therefore, the researchers have been refining and adjusting to the basic competence.

2) A small group Testing: The small group trial was conducted to a group of 5 students of class XI High School 
Mathematics Babussalam Pekanbaru which were selected randomly with the heterogeneous gender academic ability.

TABLE III. ThE SCORE OF SMALL GROUP TRIAL

\begin{tabular}{|c|c|c|c|}
\hline \multirow{2}{*}{$\begin{array}{c}\text { Class } \\
\text { Meeting }\end{array}$} & \multicolumn{3}{|c|}{ Percentage of Each Aspect } \\
\cline { 2 - 4 } & Media & $\begin{array}{c}\text { Teaching } \\
\text { Material }\end{array}$ & Program \\
\hline 1 & $95.00 \%$ & $94.67 \%$ & $90.67 \%$ \\
\hline 2 & $94.00 \%$ & $85.33 \%$ & $84.00 \%$ \\
\hline 3 & $98.00 \%$ & $90.00 \%$ & $86.67 \%$ \\
\hline 4 & $96.00 \%$ & $91.33 \%$ & $86.67 \%$ \\
\hline 5 & $97.00 \%$ & $91.33 \%$ & $88.00 \%$ \\
\hline 6 & $93.00 \%$ & $86.67 \%$ & $84.00 \%$ \\
\hline $\begin{array}{c}\text { Total } \\
\text { Percentage }\end{array}$ & $95.5 \%$ & $89.88 \%$ & $86.66 \%$ \\
\hline Category & Very Good & Very Good & Very Good \\
\hline
\end{tabular}

The results of students' responses from the small group trial demonstrated an excellent success rate, characterized by the total percentage of every aspect of $\geq 85 \%$ and positive comments from students. Based on the results of student responses on the small group trial, the prototype media has got a very good response.

3) Large group trial: In the large group trial, prototype revision based on suggestion of the small group trial was tested toward 30 students of class XI at High School Mathematics Babussalam. This was done to see the students' response to computer-based learning media using model of interactive tutorials, and students' responses can be seen in Table 4.

TABLE IV. The SCORE OF LARGE GROUP TRIAL

\begin{tabular}{|c|c|c|c|}
\hline \multirow{2}{*}{$\begin{array}{c}\text { Class } \\
\text { Meeting }\end{array}$} & \multicolumn{3}{|c|}{ Percentage of Each Aspect } \\
\cline { 2 - 4 } & Media & $\begin{array}{c}\text { Teaching } \\
\text { Material }\end{array}$ & Program \\
\hline 1 & $88.83 \%$ & $84.78 \%$ & $86.22 \%$ \\
\hline 2 & $88.83 \%$ & $81.78 \%$ & $84.67 \%$ \\
\hline 3 & $88.67 \%$ & $85.78 \%$ & $85.56 \%$ \\
\hline 4 & $86.00 \%$ & $85.11 \%$ & $84.67 \%$ \\
\hline 5 & $87.00 \%$ & $83.89 \%$ & $84.22 \%$ \\
\hline 6 & $88.00 \%$ & $82.78 \%$ & $84.67 \%$ \\
\hline $\begin{array}{c}\text { Total } \\
\text { Percentage }\end{array}$ & $87.88 \%$ & $84.02 \%$ & $85.00 \%$ \\
\hline Category & Very Good & Very Good & Very Good \\
\hline
\end{tabular}

The score for the whole group of class meetings on aspects of the media and aspects of the program was included in the very good category, and the aspects of the subject matter obtained good category. These showed that the model of computer-based learning media using interactive tutorial for high school grade material XI on probability topic obtained a very good response

4) Product Revised: The media that has been tested on a large group was subsequently revised in accordance with the learning need in order to obtain computer-based learning media with interactive tutorial models for class XI on Probability topics at mathematics class.

\section{DISCUSSION}

The process of validating the learning media was done in four aspects: the curriculum, the learning aspect, the aspect of the display, and aspects of the program. In this study, the validators were experts of computers and learning of mathematics.

Based on the analysis of the validation results from the aspects of the curriculum, the learning aspect, the aspect of the display, overall program, it can be concluded that media computer-based learning is valid, with an average of all aspect $\geq 3$. This result means that computer-based learning media with interactive tutorial models for class XI SMA on probability topic can be used as one of the media in carrying out the learning of mathematics in particular on the topic of probability.

The responses to computer-based learning media model of interactive tutorials for class XI SMA on probability topic were obtained from the student questionnaire. From the questionnaire, it can be concluded that the learning media obtained a very good response to the total percentage of the third aspect of the class meeting $\geq 85 \%$. The students claimed that they could operate the media with easily. Display on media was very interesting and easy to understand. The students also stated that the animation in this learning media was interesting and helpful in understanding the material. From the results of student questionnaire, it can be concluded that computer-based learning media with the model of interactive tutorial for high school Grade XI on probability topic can be used as a learning media for probability topic.

\section{CONCLUSION AND RECOMMENDATION}

This development research produced a learning media in the form of computer-based media with model of interactive tutorials for Class XI SMA on probability topic. This Mathematics learning media has been validated and had two trials. From the results of the validation and testing, it was found that the development of computer-based learning media with interactive tutorial models for class XI SMA on probability topic was regarded valid and received a very good response from students. 
The researchers give some recommendations in relation to the development of research as follows:

1. This research has produced a valid instructional media and got a very good response. This media is very good due to the attractive presentation of the material with good animation and its easiness to operate. Therefore, the media that has been developed should be used as the learning media in studying mathematics, especially probabiltiy topic.

2. In this study the researchers restricted the media research only to the validity of the results and the students' responses to learning media. These open an opportunity for other researchers to look at the effect of using instructional media on student learning outcomes or other aspects of learning.

3. This learning media needs computers as means of learning support. The schools that want to use this media should provide computer facilities in schools.

4. Teachers need to have basic computer skills to use this media. If required, this media can be modified in accordance with the needs of teachers.

\section{ACKNOWLEDGMENT}

This research involve validators and students in process of development, so the researchers appreciate their contribution in producing this learning media.

\section{REFERENCES}

[1] A. Arsyad, Media Pembelajaran. Rajawali Press. Jakarta, 2005.

[2] H. B. Uno, Profesi Kependidikan: Problema, Solusi, dan Reformasi Pendidikan di Indonesia. PT Bumi Aksara. Jakarta, 2008.

[3] A. Jaromfr. "Teaching Probability at Secondary School Using Computer", Intenational Statistical Institute, $56^{\text {th }}$ Session, 2017.

[4] N. Busadee. 2012. Authentic Problems in High School Probability Lesson: Putting Research into Practice. Available from: https://www.researchgate.net/publication/275542635 Authentic Proble ms_in_High_School_Probability_Lesson_Putting_Research_into_Practi ce [accessed Apr 15, 2017].

[5] G. Muruganantham, "Developing of e-content package by using ADDIE model," International Journal of Applied Research,. 1(3): 2015, pp.52-54. 